\title{
Enhance the Educational Outcome in Higher Educational Institutes through Deep Neural Network
}

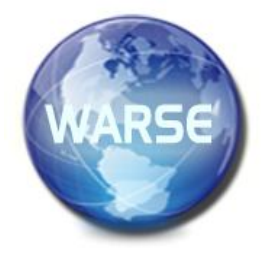

\author{
Veerraju Gampala ${ }^{1}$, Anupriya Koneru ${ }^{2}$, Balajee Maram $^{3}$ \\ ${ }^{1}$ Department of Computer Science and Engineering, \\ Koneru Lakshmaiah Education Foundation, \\ Vaddeswaram, Guntur, Andhra Pradesh 522502, India. \\ ${ }^{2}$ Associate Professor, Department of Information Technology, \\ Lakireddy Bali Reddy College of Engineering, \\ Mylavaram, Andhra Pradesh, India. \\ ${ }^{3}$ Associate Professor, Department of CSE, \\ GMR Institute of Technology, \\ Rajam, Srikakulam, Andhra Pradesh, India.
}

\begin{abstract}
Nowadays, the main aim of every engineering college or university is the improvement of the educational outcome. The student's academic performance mainly impacts the educational outcome of any college. Measuring students' performance is a challenging issue that can help students and teachers to keep track progress of student performance and there by mentoring less performance students to obtain the highest grade in their final exams. The present work will help in predicting the performance of every student within 2 weeks of 16 weeks instruction period using previous outcome in various examinations and some additional parameters also effects the students' academic performance such as attendance, health issues, etc. Based on the predicted results student can be monitored to improve his/her abilities. To achieve this, this study proposes a deep multilayer feed forward neural network (MFFNN) model. The proposed model is used to predict the performance of every individual for a single subject or a course with high accuracy. In this paper, a dataset is generated based on the previous exam grades and a set of handcrafted features of students. The results indicate the proposed MFFNN model achieves an accuracy of $89.19 \%$ - $93.89 \%$. The proposed model outperforms the support vector machine. While the support vector machine achieves $76.71 \%-88.6 \%$. This study makes an open door for recognizing students who may graduate with poor outcomes or may not graduate at all, and also to assist intuitions and instructors for early intervention.
\end{abstract}

Key words: Educational outcome, Monitoring, Deep Learning Techniques, Deep Neural Network, Prediction.

\section{INTRODUCTION}

Education plays a vital role in the development of a nation [16]. The future of any country majorly dependents on the technology and knowledge advancements provided by the sector of higher education. One way to accomplish the quality higher education is by forecasting students' performance in advance, subsequently taking early activities to improve the students' performance and quality training. In the developing world, the Engineering capacity should be taken to expand personal satisfaction. For highly qualified engineers to achieve local and global hassles, universities face the pressure. To build strategies for future development and further actions, educational organizations are utilizing educational frameworks to examine their performance. To help the institutes, to gain more new students and retain old students, the actions mainly focus on finding and developing methods that can improve student academic performance. In our current educational systems, student performance prediction is worst day-by-day. In advance, if we can predict the performance of students, then it can improve the student level activities, and maintain the quality of education by predicting subject interests of students, and assists in their performances in educational institutes or universities. Students' scholastic performance depends on different elements like individual, financial, mental, and other ecological factors. So, measuring the academic performance of students in advance is a challenging task.

To achieve this challenging task, the authors of [7] proposed ML algorithms-based techniques for student path prediction and provide feedback of the students and also predictive and perspective analytics for the forecasting outcomes in the future using the Smart Learning Analytics (SLA) conceptual model. The authors present the findings and results of research. Design development (R\&D) project at an inter labs research institute intended that a setup and 
bench marking of various ML algorithms for foretelling analytics of students' educational performance in science, technology, engineering, and mathematics (STEM) courses. It is used in advance systems for academic analytics includes Linear Regression, Logistic Regression, Artificial Neural Network, Random Forest Classification, and SVM Classification. They performed a formative and summative survey of students. It is clearly shows the students' interest in academic performance in a course. Over the coming decades, STEM associated job areas are anticipated to enlarge.

The deep learning techniques are the most noticeable methods used for the Educational Data Mining (EDM). Deep leaning is developed from the machine learning and portrayed using the quantity of computational layers that empowers the model to gain from models, patterns, events, and hand crafted features [17]. The authors of [11] are employed deep Learning methods like Deep Neural Net and Data Mining strategies like Random Forest, SVM, and Naïve Bayes are applied on the dataset using tools such as Weka and Rapid Miner. They observed that Deep Neural Network outstands in forecasting students' performance compared to other methods. Some authors [3] are extracted the students' dataset from the virtual learning environment and to predict the students' performance, they employed kNN, SVM, and ANN.

To analyze the students' performance, deep learning is one of the most popular technique. An increase in the educational data of e-learning systems, and even progressing traditional education, deep learning is gaining more attention. The present work will help in predicting the performance of every student within two weeks, eight weeks, and sixteen weeks of 16 week's instruction period using the previous outcomes in various examinations and some personal information. The prediction of student performance is necessary because to increase course effectiveness, when the number of predicted failures are more, it may be because of the ineffective syllabus, so that the syllabus can be reassessed and improved. In order to enhance the student performance primary warning of high-risk students can be predicted, which can help teachers to keep the attention on them. At an early stage to increase the success rate our present work provides a better ability to forecast student performance. The main contributions of this research work are:

- The creation of dataset by taking student data from the university database and some personal information of students.

- $\quad$ Predicting the students' performance in three phases using the proposed deep neural network: after two weeks, after eight weeks, and after sixteen weeks.

- Performance metrics of the proposed MFFNN model are compared with SVM technique.

The rest of the paper is prepared as follows: the literature work is elaborated in the section 2, the methods and methodology used in the paper is discussed in section 3, the dataset preparation is presented in the section 4, the experiment results and discussion is visually analyzed in section 5, and finally the conclusions are presented in section 6.

\section{RELATED WORK}

The students' performance in higher education is a multidimensional and can be elaborated and analyzed through multiple factors, including a primary prediction of dropouts and withdrawal of ongoing courses, analyzing important factors impacting the students' performance and installing statistical methods to quantify their performance. Many researchers are proposed several data mining and AI (example machine learning) techniques to predict the students' performance. The achievement of the students can be measured by the student communication with the virtual content and based on the performance of each student the result is categorized into following withdrawn, pass, fail, and distinction in order to forecast at-risk of failure students and provide measures for primary interference of such students [1]. To build the model, they are used Deep ANN with the Support Vector Machine (SVM) and Logistic Regression (LR) on the data.

In the study of Aderibigbe et al., [2], prophetic study was conceded out to direct the degree to which Cumulative Grade Point Average (CGPA) in the fifth year of engineering undergraduates can be determined. The program and the year of admission were passed as prognostic inputs into a Konstanz Information Miner (KNIME). Six different data mining techniques were implemented independently in order to compare the outcomes of the algorithms. The authors of [3] employed a dataset, which includes students' assessment grades and logs of their communications with the Virtual Environment. To classify the performance of the student. They employed k-NN, Support Vector Machines (SVM), Artificial Neural Networks (ANN), Naïve Bayes and Logistic Regression in order to predict the students' performance.

An online ensemble utilizing the voting approach is proposed [4] in order to join three classifiers such as The Naive Bayes, the 1-NN and WINNOW systems. The proposed technique helps instructors to identify which of their students will finish a module or a course with adequately precise precision. This technique is regularly unfeasible both regarding space and update time for online settings with asset limitations. To redress the space issue, they confined the size of the dataset through putting away and using the latest or most critical examples. The authors of [5] proposes a new model, called Students Performance prediction using Relational Association Rules (S PRAR) to predict the final grade of a student using relational association rules. In this, the datasets contain the grades of students in the first, second and third semesters at BabesBolyai University. The drawbacks of S PRAR are that it is not appropriate for prediction issues. Six classification algorithms have been used in [6], which are widely used among the machine learning community. They constructed WEKA - Decision tree learner using J48 in WEKA. They 
conducted experiments on three different K-Nearest neighbor classifiers, 1NN, 3NN, 5NN, Navie - Bayes CNB, RIPPER, Rule - based learner, SVM, SMO. They combined NB and 1-NN with feature selection to accurately predict the student's final performance. The authors of [7] present the findings and results of a research, design development (R\&D) project at an inter labs research institute, Bradley University (USA) intended that a setup and bench marking of various ML algorithms for prognostic analytics of student educational performance in STEM courses. It is used in advance systems for academic analytics includes Linear Regression, Logistic Regression, Artificial Neural Network, Random Forest Classification, and SVM Classification. They performed a formative and summative survey of students.

The authors [8] proposed a novice machine learning tool which can find the predictions of the future score. In this, they are using the multiple linear regression, Decision tree regression, K - Nearest neighbor. They observed multiple linear regression model gives optimal solution. Additionally, the students with low predicted scores are assigned with the tutor. The authors [9] propose an ML model to predict whether the student would accomplish a grade less than 5 or not in a set of 7 exams applied throughout the course and in the final examination and in order to perform optimization in ML pipelines, an automated method with an evolutionary algorithm and hyper parameter tuning with a random search is proposed. In this study [10], the authors employed AI techniques to detect low engagement students in social science subject to assess the effect of assignation on student performance. The prime motto of the authors of this study [11] is to find the performance of students utilizing some classification procedures and finding the best one, which yields ideal outcomes. They collected instructive dataset from a Saudi University database. Deep Learning methods like Deep Neural Net and Data Mining techniques like Random Forest, SVM, and Naïve Bayes are taken and applied on the dataset using Rapid Miner tools and Weka.

In this research study [12], the authors are elaborated how AI (machine learning) models can aid to expand an education system through various factors in results such as accuracy, Precision, Recall, F-Measure, etc. This work [13] objective is to design a structure of a canny recommender framework that can anticipate students' first year scholarly execution and suggest vital activities for development. The principle point of this paper [14] is to build the displaying precision of students' performance through two procedures dependent on factor choice and dimensionality decrease. The study [15] focused on three information sources: Student Record System (SRS), the Learning Management System (LMS) and Survey and furthermore utilized three condition of-workmanship information mining classifiers: Decision Tree (DT), Artificial Neural Network (ANN) and Support Vector Machine (SVM) for the demonstrating.

The authors [19] present a basic report on pertinence of Sokoban game for evaluating understudy's mental factors so an Expert framework can assemble a psychological model of an understudy for career assessment. The authors [20] propose a system that can be used in schools, colleges and other educational institutions to assess student performance. The authors [21] build up a specialist framework for anticipating the profession by evaluating mental elements of a student like critical thinking capacity, knowledge and tolerance levels. The authors [22] done near examination on various calculations utilizing Weka apparatus to know the best classification calculation so as to foresee the students' activity. The authors [23] propose an expert system for student career assessment, in which, they gave some questions to students and answering these questions confirms student abilities.

The authors [24] propose method using the machine learning techniques in order to forecast the student' performance. The authors [25] analyzed and implemented various machine learning techniques to forecast students' performance. The authors [26] propose a model to assist the students with knowing their weak territories and makes crafted by enrollment specialist simpler. This model likewise encourages the student to know which classification they have a place, Such that they attempt to develop themselves. The authors [27] propose a model to assess the student memory power through the recollection of words and names of the persons that are displayed. The authors [28] propose a choice taking the framework for students to choose their scholarly branch interests. The authors [16] propose a method to use classification and cyclomatic complexity to predict the quality of the source code by givingpublic data sets as input.Riyanto Jayadi et al. [17] present an employee performance prediction in a company usingmachine learning.The authors [29] propose a prediction-based model for student dropouts using modified mutated firefly algorithm. The authors [30] propose a deep learning model to forecast corona virus.

\section{DATASET PREPARATION}

The dataset used for the present work is the academic records of the students of a computer science department from the GMR Institute of Technology. The dataset consists of details regarding the student's personal info, academic info like marks, courses, and some special features like health, attendance for each interval are also included for a better prediction. Dataset attributes are described in Table 1.

Table 1: Dataset description

\begin{tabular}{|l|l|l|}
\hline S.no. & \multicolumn{1}{|c|}{$\begin{array}{c}\text { Attribute or } \\
\text { Feature }\end{array}$} & \multicolumn{1}{|c|}{ Description } \\
\hline 1 & Course_Code & $\begin{array}{l}\text { A unique number which } \\
\text { contains two letters for } \\
\text { departmental code (to represent } \\
\text { the course to which department } \\
\text { it belongs) a three- or four- } \\
\text { digits subject code and a two- } \\
\text { digit number for year of } \\
\text { regulation. }\end{array}$ \\
\hline 2 & Course_Semester & $\begin{array}{l}\text { Studying a specific course for } \\
\text { half year at a university or }\end{array}$ \\
\hline
\end{tabular}




\begin{tabular}{|c|c|c|}
\hline & & $\begin{array}{lrl}\text { college is } & \text { called } \\
\text { course_semester. } & \end{array}$ \\
\hline 3 & Student_ID & $\begin{array}{l}\text { Student Identification number } \\
\text { is a unique identifier to every } \\
\text { student. Student_ ID is } \\
\text { connected to college records. }\end{array}$ \\
\hline 4 & Age & Age of the student. \\
\hline 5 & $\begin{array}{l}\text { Mid1 (descriptive } \\
\text { 1) Marks }\end{array}$ & $\begin{array}{l}\text { Mid1 exams are conducted for } \\
\text { the first half of the semester. } \\
\text { Mid1 Marks are calculated } \\
\text { based on the performance of a } \\
\text { student. }\end{array}$ \\
\hline 6 & $\begin{array}{l}\text { Mid2 (descriptive } \\
\text { 2) Marks }\end{array}$ & $\begin{array}{l}\text { Mid2 exams are conducted for } \\
\text { the second half of the semester. } \\
\text { Mid2 Marks are calculated } \\
\text { based on the performance of a } \\
\text { student. }\end{array}$ \\
\hline 7 & $\begin{array}{l}\text { Comprehensive } \\
\text { Marks }\end{array}$ & $\begin{array}{l}\text { Comprehensive exams are one } \\
\text { of the internal exams to } \\
\text { calculate the student } \\
\text { performance. }\end{array}$ \\
\hline 8 & Health Issues & $\begin{array}{l}\text { It indicates whether the student } \\
\text { has any health issues. Health } \\
\text { issue occurs when the normal } \\
\text { metabolism of a student failed } \\
\text { or altered. Health issues like } \\
\text { fever, injury, heart disease, } \\
\text { cancer, etc. which affect } \\
\text { students' performance. }\end{array}$ \\
\hline 9 & Sports & $\begin{array}{l}\text { Sports leads to increase } \\
\text { concentration on studies, } \\
\text { enhance memory, stimulate } \\
\text { activity and develop problem } \\
\text { solving skills. So, playing } \\
\text { sports can also increase the } \\
\text { performance of a student. }\end{array}$ \\
\hline 10 & Events & $\begin{array}{l}\text { Participation in events boosts } \\
\text { self-confidence, which effects } \\
\text { student performance. }\end{array}$ \\
\hline 11 & $\begin{array}{l}\text { Intermediate } \\
\text { aggregate }\end{array}$ & $\begin{array}{l}\text { Good marks show hard work } \\
\text { of the student, talent and } \\
\text { dedication towards their study } \\
\text { and seriousness about their } \\
\text { career. Inter score plays a } \\
\text { major role in predicting the } \\
\text { performance of a student. }\end{array}$ \\
\hline 12 & $\begin{array}{ll}10^{\text {th }} & \text { class } \\
\text { aggregate } & \end{array}$ & $\begin{array}{l}\text { Marks determine the } \\
\text { performance of a student. To } \\
\text { forecast whether the student } \\
\text { gets distinction, pass or fail in } \\
\text { his final exams, school score is } \\
\text { also an important factor. }\end{array}$ \\
\hline 13 & Social_act & $\begin{array}{l}\text { Social activities like } \\
\text { volunteering, sports teams, } \\
\text { social clubs, etc helps to } \\
\text { improve social skills and } \\
\text { interaction with various types } \\
\text { of people helps to expand their } \\
\text { network, which is beneficial }\end{array}$ \\
\hline
\end{tabular}

\begin{tabular}{|c|c|c|}
\hline & & for finding a good career. \\
\hline 14 & Sem & $\begin{array}{l}\text { A semester system divides the } \\
\text { academic year into two halves. } \\
\text { Each half is approximately } 16 \\
\text { weeks }\end{array}$ \\
\hline 15 & Batch & $\begin{array}{l}\text { The joining and the relieving } \\
\text { year of a student is known as } \\
\text { batch. }\end{array}$ \\
\hline 16 & Gender & The student's gender. \\
\hline 17 & $\begin{array}{l}\text { Late assignment } \\
\text { submission }\end{array}$ & $\begin{array}{l}\text { Late assignment submission } \\
\text { indicates that the student is } \\
\text { lazy and not dedicated to } \\
\text { his/her work. }\end{array}$ \\
\hline 18 & Organizing & $\begin{array}{l}\text { By organizing events, students } \\
\text { can develop leadership } \\
\text { qualities such as integrity, } \\
\text { confidence, commitment, } \\
\text { passion and decision-making } \\
\text { capabilities. }\end{array}$ \\
\hline 19 & Coding skills & $\begin{array}{l}\text { Coding skills helps a student to } \\
\text { create computer software, apps } \\
\text { and web-sites. Apart from the } \\
\text { academic knowledge, the } \\
\text { student should have coding } \\
\text { skills too. }\end{array}$ \\
\hline 20 & $\begin{array}{l}\text { Communication } \\
\text { skills }\end{array}$ & $\begin{array}{l}\text { Speaking skills allow the } \\
\text { speaker to convey his message } \\
\text { in a proper way. In addition to } \\
\text { academic knowledge, a student } \\
\text { should have speaking skills. }\end{array}$ \\
\hline 21 & Backlogs & $\begin{array}{l}\text { The backlog is used to refer the } \\
\text { number of failed courses that } \\
\text { haven't been cleared. }\end{array}$ \\
\hline 22 & Achievements & $\begin{array}{l}\text { Achievements like paper } \\
\text { presentations, Hackathons, } \\
\text { debates, etc. improves the } \\
\text { students' performance. }\end{array}$ \\
\hline 23 & Attendance & $\begin{array}{l}\text { a) Timeperiod1: Total no } \\
\text { of classes attended for the } \\
\text { course in a semester during the } \\
\text { mid-1 phase. } \\
\text { b) Timeperiod2: Total no } \\
\text { of classes attended for the } \\
\text { course in a semester during } \\
\text { mid-2 phase. } \\
\text { c) Timeperiod3: Total no } \\
\text { of classes attended for the } \\
\text { course during the entire } \\
\text { semester. }\end{array}$ \\
\hline
\end{tabular}

\section{METHODOLOGY}

In this section, the methodology employed for this research work starts with data collection from college academics and students followed by data cleaning and feature selection. Next phase is a model building. In this step deep neural network namely multilayer feed forward neural network (MFFNN) is proposed for model construction that can predict the students' performance and after predicting the 
performance of each student, the model can give required suggestions for making the student better in academics.

\subsection{Data Collection}

The past performance of student data is collected from the college academic database, and student personal information such as habits, etc. is also collected, which is used as training set for student performance prediction.

\subsection{Data Cleaning:}

In this phase, the dataset is required to be reduced by excluding all the attribute data that are not affecting the students' performance. This feature reduction can be done in many ways. One of the best way is using SVD (Singular ValueDecomposition), SVD is a mathematical matrix decomposition method of minimizing a complex matrix into a simple matrix.

The performance of a student is predicted in 3 interval phases.

Phase 1: In this phase, the performance of a student is predicted using his/her mid-1 marks in the current semester and previous performance data.

Phase 2: If the student belongs to AR16 regulation, then $80 \%$ from best of mid 1 and mid 2 marks is added to $20 \%$ of other mid exam marks, which are given as a test set to the model. If a student belongs to any other regulation, then the average of two mids is given as a test set.

Phase 3: In this phase, the final performance of a student (AR16) is predicted using his/her mid1 marks, mid2 marks and comprehensive marks.

\subsection{Proposed Model Building}

After creating dataset using academic features and student additional features, the reduced feature dataset is passed to the proposed MFFNN deep learning algorithm. The proposed deep neural network architecture is shown in Fig. 1.

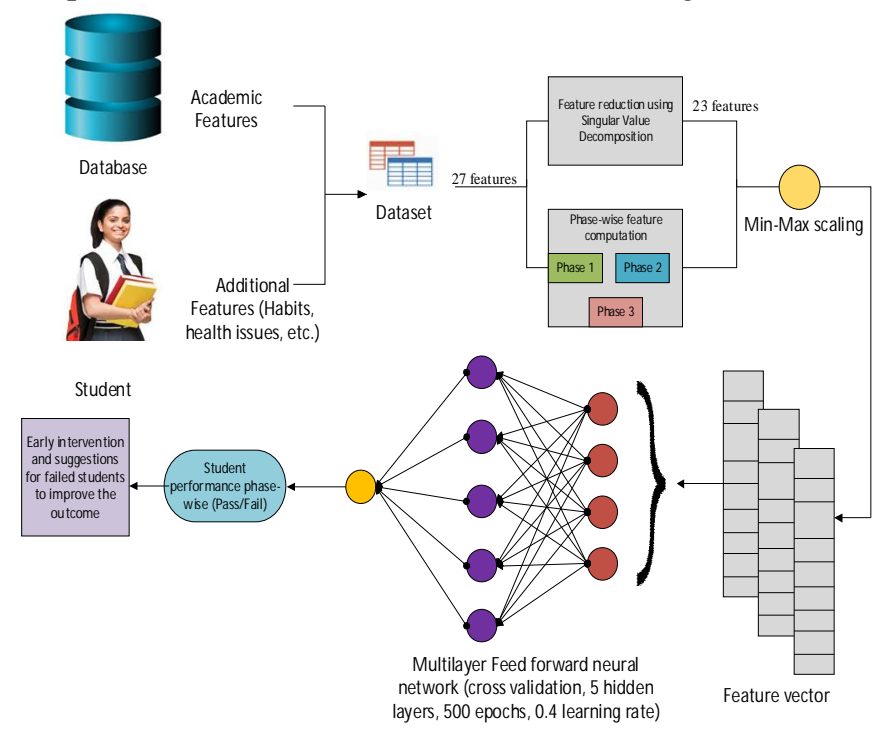

Figure 1: Proposed architecture for multilayer feed forward deep neural network.

In the present work, back-propagation algorithm is used for developing the model, which is a classical multilayer feed forward artificial neural network. Forward-propagation will take the input and calculates the output. In back-propagation, error is computed among the estimated outputs and therefore the forward disseminated output from the network. Then the errors are back disseminated with in the network from the output layer to the hidden layers, and weights are updated.

The neural network is built using list and dictionaries in Python. A neural network consists of a group of layers and each layer with a group of neurons. Each neuron will hold two weights, one for input data and one for bias. The neuron is represented through dictionary variable. Then a set of dictionaries can be combined into an array, which represents a single layer. Now the whole network can be built as an array of layers. Initially, the weights of each neuron is initialized with a random value in the range of 0 to 1 .

The activation of each and every neuron is equal to the weighted sum of inputs and the bias. The following equation defines the neuron activation:

Neuron activation $=\sum\left(\right.$ weight $_{\mathrm{i}} *$ input $\left._{\mathrm{i}}\right)+\operatorname{bias}(1)$

Once the activation is calculated, then this value is transferred as the output of that neuron. The transfer function used in the present work is the sigmoid activation function.

$S(x)=\frac{1}{\left(1+e^{-x}\right)}$

Where, $\mathrm{e}=$ exponential constant

Sigmoid function takes any input value and produces a number in between 0 and 1 . It is also a mathematical function. The activation of each and every neuron is equal to the weighted sum of inputs and the bias.

The output of each neuron in each layer is given as input to each neuron on the next layer, this is called as the forward propagation.

Error is calculated using the expected output and the output from the forward propagation. After calculating errors, for each neuron through back-propagation, this error is used to update the weights using the learning rate parameter. The back propagation of outputs is completed using the function which is derivative of sigmoid function used for forward propagation.

derivative $($ output $)=$ output $*(1.0-$ output $)$

error $=($ expected - output $) *$ derivative $($ output $)$

The equation 4 is calculating error for the neurons of the output layer. For the hidden layer the error calculation is done by the following equation:

error $=\left(\right.$ weight $_{i} *$ error $\left._{j}\right) *$ derivative $($ output $)$

where, error $j$ : error from the $j^{\text {th }}$ neuron of the output layer

weight ${ }_{i}$ : weight of $i^{\text {th }}$ neuron that connects to the current neuron

The learning rate will decide how much to change the weights. For the present work, the learning rate is assumed as 0.4 . A learning rate of 0.4 will change the weights of $40 \%$. 
weight $_{\text {new }}$

$=$ weight $_{\text {old }}$

+ (learning rate $*$ error

* input)

In this research work, feed forward neural network is employed to forecast the students at risk of fail and students who outperforms. Fig. 2 demonstrates the proposed level wise architecture of MFFNN. After selecting 27 features from academics and students, singular value decomposition is employed for feature reduction. Similarly, features are selected for each phase of prediction. The work flow of the model is depicted in Fig. 2. The reduced features of each phase are passed through min-max scaling to regularize the data. Next, the dataset is divided into a train and test set using $\mathrm{k}$-fold cross validation and fed to MFFNN model in the form of feature vector. In this model, 500 epochs are used for training. In every epoch, the whole network will be updated and the entire training dataset is passed through the network. The network is improved for each epoch. As a result, a large number of epochs leads the model more effective. Based on the dataset size, the hidden layers of present work are fixed to 5 layers and learning rate is 0.4 , which will be sufficient for the present work. The student performance is predicted in three phases: after the descriptive 1 exam, after descriptive 2 , and after the comprehensive exam. The students who not performed well or fail are identified at each phase and gives counselling and suggestions in order to enhance the performance in the successive phase. It will compare the given test data labels, and the predicted test data labels to calculate the accuracy.Further, the detailed experimental work is provided in the next section.

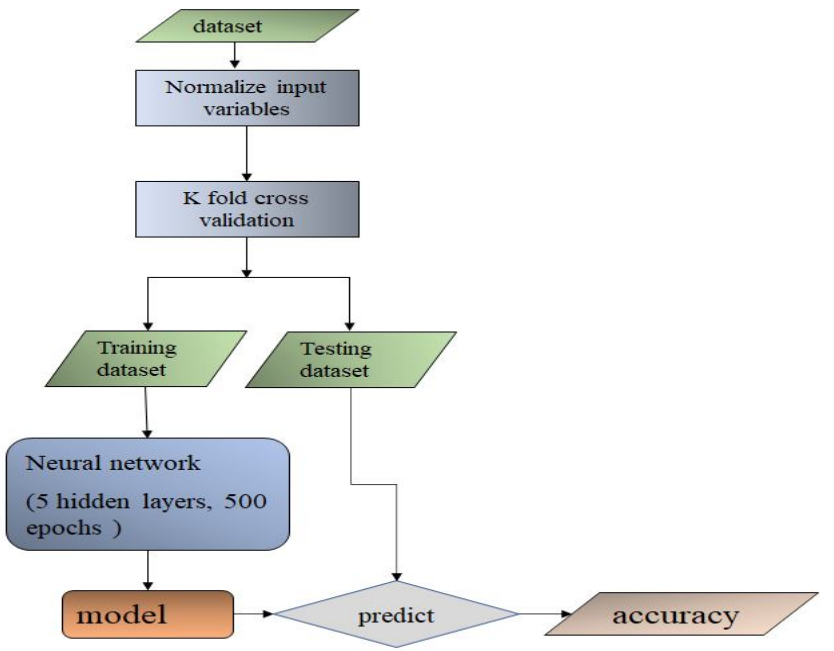

Figure 2: The proposed MFFNN model work flow.

\section{RESULTS AND DISCUSSION}

This section deliberates the main aspects of experimental work accomplish in this study. The whole data analysis and the proposed model development are coded in Python 3 and executed in the Google Colab research framework with 12.72 GB RAM and Google Compute Engine backend [18]. In This study, the student performance is evaluated in three interval phases (time periods): 1) after first descriptive exams, 2) after second descriptive exams, and 3) after comprehensive exams. At each phase, the performance of students are predicted using back-propagation algorithm which is a deep learning technique. In back-propagation algorithm, if there exist any errors, then the errors are back propagated in the network. As a result, this model yields better results compared to other literature algorithms. For each of those phases, various experiments are conducted with prescribed features data. As a result, enhanced results are acquired when the proposed MFFNN model is deployed with five hidden layers of different neurons, 500 epochs, and 0.4 learning rate.

\subsection{Analysis of Categories}

To predict the students' performance, considering their descriptive exam results, other previous academic information of student, and student personal information, 23 features, through the singular value decomposition reduction method are selected from a total of 27 features, shown in Table 1. The evaluation results of the proposed MFFNN method with the preexisted model Support Vector Machine (SVM) are presented in Table 2. The cross validation is applied on the dataset. The proposed and baseline models are implemented various times with an arbitrary train and test set data, and the resultants are averaged and presented in Table 2.

\subsubsection{Forecasting Failure Students}

The students at risk of failure is converted into binary classification with two classes pass and fail. MFFNN method yields a better accuracy with five hidden layers of 40 neurons each than SVM with an rbf kernel. From results, It is perceived that academic features, previous academic performance, students' bequest data such as submission of assignments, and the whole activities of a student in the phases are considerably impact the performance in predicting students' at risk of failure. Moreover, the proposed MFFNN produces accuracy of $89.19 \%$, which is better than base line model SVM (see Table 2). The performance of proposed MFFNN model is compared with baseline model depicted in Fig. 3.

\subsubsection{Forecasting First-Class Students}

To predict first-class students, this problem is considered as a binary classification problem. It is divided into two set of categories: 'first-class and pass' and 'first-class and fail'. MFFNN with 5 hidden layers of 40 neurons each and sigmoid as activation function yields optimal results for 'first-class and pass' category. As per Table 2, the accuracy of MFFNN in 'first-class and pass' category doesn't have much difference with SVM model. This is because class imbalance problem, and also both classes have almost same pattern of features. In the 'first-class and fail' category, MFFNN yields more accuracy than SVM, as presented in Table 2. Parameters are tuned as like previous category. To predict first-class students from at risk of failures, academic performance of students is observed, and it is positively associated with this category, whereas students' personal 
information and academic history are deleteriously associated with the students' performance.

students performance category-wise

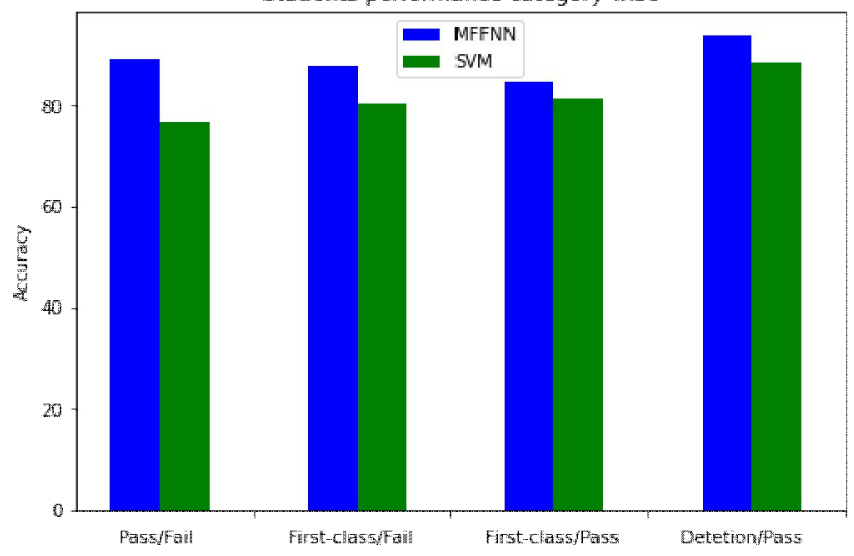

Figure 3: Accuracy of MFFNN model with baseline SVM.

\subsubsection{Forecasting Detention Students}

To predict detention students, two classes such as detention and pass are defined. The pattern of features for detention are different from pass cases, since detentions are tend to leave the current academic year in their carrier. He/she has to study the same academic year once again in the successive year. Parameters of MFFNN are tuned with 5 hidden layers of 40 neurons each and sigmoid activation function. MFFNN acquires $93.98 \%$ accuracy in predicting the two class labels, which is higher than SVM, as shown in Table 2. In case of detentions, the student personal information, student attendance, and health issues in the semester are observed to be significantly impacting this category. The accuracies of the proposed MFFNN model with baseline SVM are depicted in Fig. 3.

Table 2: Averaged cross validation results of students for each category

\begin{tabular}{|l|l|l|l|}
\hline Categories & Methods & Accuracy & Loss \\
\hline Pass/Fail & MFFNN & 89.19 & 0.16 \\
\cline { 2 - 4 } & SVM & 76.71 & 0.21 \\
\hline \multirow{3}{*}{ First-class/Fail } & MFFNN & 88.15 & 0.16 \\
\cline { 2 - 4 } & SVM & 80.59 & 0.21 \\
\hline First-class/Pass & MFFNN & 84.45 & 0.14 \\
\cline { 2 - 4 } & SVM & 81.47 & 0.18 \\
\hline \multirow{2}{*}{ Detention/Pass } & MFFNN & 93.98 & 0.09 \\
\cline { 2 - 4 } & SVM & 88.6 & 0.16 \\
\hline
\end{tabular}

Fig 3 illustrates that the proposed deep learning technique gives better results than Support Vector Machine (SVM). In SVM, as the categories increase or decrease, there is little change in accuracy. The accuracy of SVM for four categories is $76.71,80.59,81.47$, and 88.6, but in deep learning as the number of categories increase, the outputs obtained are more accurate. The accuracy obtained by deep learning are $89.19,88.15,84.45$, and 93.98 with respective four categories. With the increase in size and features of dataset will make the proposed deep learning algorithm effective.

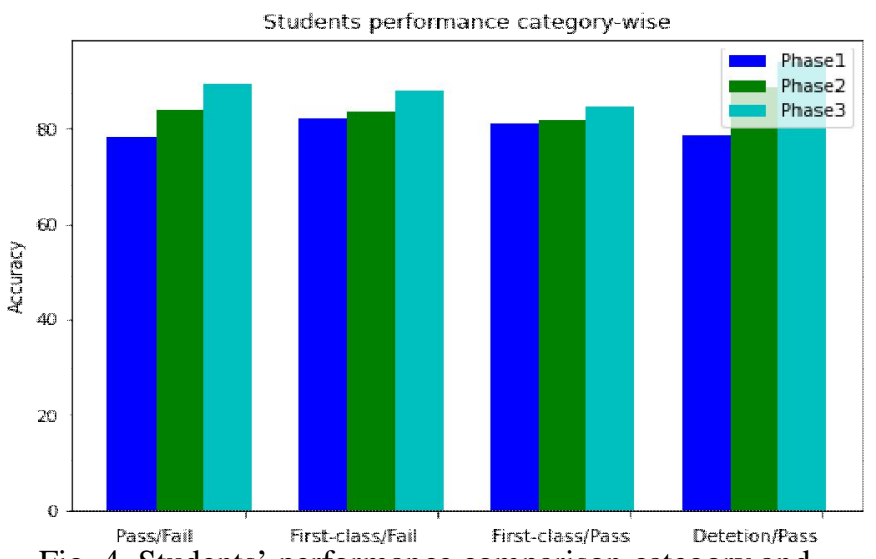

Fig. 4. Students' performance comparison category and phase-wise.

\subsection{Analysis of Students' Performance Phase wise}

To analyze the performance of student phase-wise, four categories related to failure, first-class, and detention students are predicted through the proposed MFFNN model. The detailed analysis of each phase is discussed below and presented in Table 3 and depicted in Fig. 4.

\subsubsection{Early Forecast of Failure Students}

In order to analyze the proposed model, failure students are predicted in each phase, insinuating the primary forecast of failure students. Fig. 4 shows the accuracy of each category in each phase. From the figure, it can be observed that last phase is acquired best accuracy than other phases because that contains cumulative features of all phases. However, the remaining two phases are also achieved good accuracy of above $80 \%$ when compared to baseline SVM model. Hence, the proposed model acquires an accuracy of $79-86 \%$ for early forecast of students with failure grade from the first phase to last phase respectively.

\subsubsection{Early Forecast of First-Class Students}

To forecast students outperforming with first-class, this problem is categorized into two sets: 'First-class/Pass' and 'First-class/Fail'. For the category First-class/Pass, it can be observed that the accuracy is little change or raise for all the phases (see Fig. 4). The accuracy in this category for all the phases remains putrefied, with a little variance in the final phase. It indicates that the distinct decision boundary is not available in case of First-class/Pass. This leads a problem called class imbalance, since 'First-class' cases are slightly infrequent as collated to 'pass' cases. If the 'First-class' cases are raised, then the pattern of features between students may be pictured distinctly. Also, to estimate the 'Firstclass/Fail' cases, the MFFNN model is executed on the set of cases for all the phases. The pattern difference is not observed in the first two phases due to imbalance problem. But, the last phase is acquired better accuracy than the first two phases due to low number of 'first-class' cases.

\subsubsection{Early Forecast of Detention Students}

To forecast students with the detention grade, the problem is classified as binary using detention and pass labels. It is observed that the accuracy is raised with respect to each 
phase, and the last phase is reached an almost overall accuracy of $94 \%$. Fig. 4 demonstrates the prediction of detention cases and pass cases. It can be observed that the proposed model continuously acquires the pattern of features for detentions for each new phase, with an accuracy varying from $80 \%$ to $94 \%$.

Table 3:Students' performance comparison category and phase-wise.

\begin{tabular}{|c|c|c|c|c|}
\hline Phases & Categorie & Methods & Accuracy & Loss \\
\hline \multirow{8}{*}{$\begin{array}{c}\text { Phase 1 } \\
\text { (after } \\
\text { descriptive 1 } \\
\text { exam) }\end{array}$} & \multirow{2}{*}{ Pass/Fail } & MFFNN & 78.381 & 0.19 \\
\hline & & SVM & 72.603 & 0.23 \\
\hline & \multirow{2}{*}{$\begin{array}{l}\text { First- } \\
\text { class/Fail }\end{array}$} & MFFNN & 82.27 & 0.18 \\
\hline & & SVM & 79.59 & 0.12 \\
\hline & \multirow{2}{*}{$\begin{array}{l}\text { First- } \\
\text { class/Pass }\end{array}$} & MFFNN & 81.17 & 0.17 \\
\hline & & SVM & 79.47 & 0.15 \\
\hline & \multirow{2}{*}{$\begin{array}{l}\text { Detention } \\
\text { /Pass }\end{array}$} & MFFNN & 78.6 & 0.12 \\
\hline & & SVM & 73.6 & 0.18 \\
\hline \multirow{8}{*}{$\begin{array}{c}\text { Phase } 2 \\
\text { (after } \\
\text { descriptive } 2 \\
\text { exam) }\end{array}$} & \multirow[t]{2}{*}{ Pass/Fail } & MFFNN & 83.99 & 0.17 \\
\hline & & SVM & 81.603 & 0.19 \\
\hline & \multirow{2}{*}{$\begin{array}{l}\text { First- } \\
\text { class/Fail }\end{array}$} & MFFNN & 83.69 & 0.14 \\
\hline & & SVM & 80.58 & 0.15 \\
\hline & \multirow{2}{*}{$\begin{array}{l}\text { First- } \\
\text { class/Pass }\end{array}$} & MFFNN & 81.98 & 0.21 \\
\hline & & SVM & 79.42 & 0.25 \\
\hline & \multirow{2}{*}{$\begin{array}{l}\text { Detention } \\
\text { /Pass }\end{array}$} & MFFNN & 88.78 & 0.11 \\
\hline & & SVM & 84.56 & 0.15 \\
\hline \multirow{8}{*}{$\begin{array}{c}\text { Phase } 3 \\
\text { (after } \\
\text { comprehensi } \\
\text { ve exam) }\end{array}$} & \multirow[t]{2}{*}{ Pass/Fail } & MFFNN & 89.19 & 0.16 \\
\hline & & SVM & 76.71 & 0.21 \\
\hline & \multirow{2}{*}{$\begin{array}{l}\text { First- } \\
\text { class/Fail }\end{array}$} & MFFNN & 88.15 & 0.16 \\
\hline & & SVM & 80.59 & 0.21 \\
\hline & \multirow{2}{*}{$\begin{array}{l}\text { First- } \\
\text { class/Pass }\end{array}$} & MFFNN & 84.45 & 0.14 \\
\hline & & SVM & 81.47 & 0.18 \\
\hline & \multirow{2}{*}{$\begin{array}{l}\text { Detention } \\
\text { /Pass }\end{array}$} & MFFNN & 93.98 & 0.09 \\
\hline & & SVM & 88.6 & 0.16 \\
\hline
\end{tabular}

\subsection{Discussions and Implications}

This paper contributes the performance of the students through the proposed MFFNN model and using significant features, which impact the students' performance. It is analyzed through four classes 'fail', 'pass', 'first-class', and 'detention'. Each of these class problem is analyzed by dividing into four categories 'pass/fail', 'first-class/fail', 'first-class/pass', and 'detention/pass'. This research work carried out through twofold analysis for all four categories. Firstly, all features of the student is considered in order to forecast the student performance. In this study, significant features are identified for each category, which impact the performance of the student, are tested. The students who are really outperforms with first-class when compared to others, it is observed that their ill health, age, and region are negatively associated with the students' performance, because the students coming from rural areas may have English problem. Personal features of a student also impact the academic performance. The students who are risk at failure or detention, overall marks or credits, previous academic history and region are found as most considerably impacting the students' performance. The age is also a key feature, which impact the detentions. As age increases, the mindset and maturity levels are increased when compare to youngsters. The most important features impacting detention is health issues. Students' health problems are impact attendance, then they will detent due to less attendance. The students actively participating in the class and submitting assignments in time positively impacting the performance of the students. The proposed MFFNN model acquires 89\% accuracy to predict students at risk of failure, which is better than baseline model SVM. Similarly, the proposed model acquires $94 \%$ accuracy to predict detention students, which is better than baseline model. The first-class students are predicted with an accuracy of $85-88 \%$, which is also slightly better than baseline model.

Phase-wise analysis is completed in the second analysis for primary intervention by the college. In this, periodically forecasts the students with failure grade using partially existing features. It is done in three phases. For example, in the first phase, the students with failure grade, detention, and first-class are predicted up to the descriptive 1 exams. The proposed model also gives suggestions to students who are chance to fail. Similarly, the remaining two phases also predicts the students at risk. The proposed model acquires $78 \%$ accuracy to predict failure students. The accuracy raises to $84 \%$ and $89 \%$ for the second and third phase with additional features data. Similarly, it is observed that the raise in accuracy from $78 \%$ to $94 \%$ for detention cases. The proposed MFFNN DL model suggests early interventions in order to motivate or counsel, and resolve the problems of students at risk. The outcome achieved in this research work can be used for the college in order to formulate guidelines for students. The early prediction of students with failure grade or detention will enable counselors for periodically monitor students and counseling them in a positive manner with appropriate suggestions and recommendations. The proposed model helps colleges and universities during every academic year to identify academically poor students, conducting them extra classes and give learning materials.

\section{CONCLUSION}

This research work contributes one of the most popular application for the early forecast of students' performance. On the basis of specific exams or assessments, students' future achievements can be estimated. This paper discovers students who are at risk of detention or failure from the specific course, and forecasting their future accomplishments from their past performance, personal information, and the final exam performance. The determinants like demographic, academic and socio-economic factors of students that affect the students' performance. There are many prediction models available with different approaches. Deep neural networks give accurate results compared to other models. The student dataset is given to the proposed MFFNN back-propagation algorithm to predict class label. By feeding the students' features data into proposed neural networks, the better accuracy is obtained when compared to baseline SVM model. To improve the learning and teaching process, early prediction of the students' performance is mostly useful to help the educators and learners. The proposed MFFNN 
model acquires $89 \%$ accuracy to predict students at risk of failure, which is better than baseline model SVM. Similarly, the proposed model acquires $94 \%$ accuracy to predict detention students, which is better than baseline model. The first-class students are predicted with an accuracy of 85 $88 \%$, which is also slightly better than baseline model. The proposed model acquires $78 \%$ accuracy to predict failure students in the first phase. The accuracy raises to $84 \%$ and $89 \%$ for second and third phase with additional features data. Similarly, it is observed that the raise in accuracy from $78 \%$ to $94 \%$ for detention cases, which is better than baseline model. The proposed model improves the educational outcomes in higher educational institutes.

As the way forward for our country lies within the welleducated youth, appropriate grooming of the student in college is a vital issue. For centralizing various educational and training activities, and proposing an appropriate mechanism to do so, plays a significant role in taking the country to great levels. A lot of areas of education should be researched using the new techniques so as to come back out with appropriate higher cognitive mechanism. We want to continue this work by broadening the scope of research to on-line education, training based educational mechanisms, peer training, and so on.

\section{REFERENCES}

1. H. Waheed, S.-U. Hassan, N. R. Aljohani, J. Hardman, S. Alelyani, and R. Nawaz, "Predicting academic performance of students from VLE big data using deep learning models,"Comput. Hum. Behav., vol. 104, p. 106189, Mar. 2020, doi: 10.1016/j.chb.2019.106189.

2. A. I. Adekitan and O. Salau, "The impact of engineering students' performance in the first three years on their graduation result using educational data mining,"Heliyon, vol. 5, no. 2, p. e01250, Feb. 2019, doi: 10.1016/j.heliyon.2019.e01250.

3. N. Tomasevic, N. Gvozdenovic, and S. Vranes, "An overview and comparison of supervised data mining techniques for student exam performance prediction,"Comput. Educ., vol. 143, p. 103676, Jan. 2020, doi: 10.1016/j.compedu.2019.103676.

4. S. Kotsiantis, K. Patriarcheas, and M. Xenos, "A combinational incremental ensemble of classifiers as a technique for predicting students' performance in distance education,"Knowl.-Based Syst., vol. 23, no. 6, pp. 529-535, Aug. 2010, doi: 10.1016/j.knosys.2010.03.010.

5. G. Czibula, A. Mihai, and L. M. Crivei, "S PRAR: A novel relational association rule mining classification model applied for academic performance prediction,"Procedia Comput. Sci., vol. 159, pp. 20-29, 2019, doi: 10.1016/j.procs.2019.09.156.

6. M. Koutina and K. L. Kermanidis, "Predicting Postgraduate Students' Performance Using Machine Learning Techniques," in Artificial Intelligence Applications and Innovations, vol. 364, L. Iliadis, I. Maglogiannis, and H. Papadopoulos, Eds. Berlin, Heidelberg: Springer Berlin Heidelberg, 2011, pp. 159168.
7. V. L. Uskov, J. P. Bakken, A. Byerly, and A. Shah, "Machine Learning-based Predictive Analytics of Student Academic Performance in STEM Education," in 2019 IEEE Global Engineering Education Conference (EDUCON), Apr. 2019, pp. 1370-1376, doi: 10.1109/EDUCON.2019.8725237.

8. N. Chauhan, K. Shah, D. Karn, and J. Dalal, "Prediction of Student's Performance Using Machine Learning,"SSRN Electron. J., 2019, doi: 10.2139/ssrn.3370802.

9. F. D. Pereira, E. H. T. Oliveira, D. Fernandes, and A. Cristea, "Early Performance Prediction for CS1 Course Students using a Combination of Machine Learning and an Evolutionary Algorithm," in 2019 IEEE 19th International Conference on Advanced Learning Technologies (ICALT), Maceió, Brazil, Jul. 2019, pp. 183-184, doi: 10.1109/ICALT.2019.00066.

10. M. Hussain, W. Zhu, W. Zhang, and S. M. R. Abidi, "Student Engagement Predictions in an e-Learning System and Their Impact on Student Course Assessment Scores," Comput. Intell. Neurosci., vol. 2018, pp. 1-21, Oct. 2018, doi: 10.1155/2018/6347186.

11. J. Sultana, M. U. Rani, and M. A. H. Farquad, "Student's Performance Prediction using Deep Learning and Data Mining Methods," vol. 8, no. 1, p. 5, 2019.

12. A. Kaur, "Machine Learning Approach to Predict Student Academic Performance,"Int. J. Res. Appl. Sci. Eng. Technol., vol. 6, no. 4, pp. 734-742, Apr. 2018, doi: 10.22214/ijraset.2018.4125.

13. M. Goga, S. Kuyoro, and N. Goga, "A Recommender for Improving the Student Academic Performance,"Procedia - Soc. Behav. Sci., vol. 180, pp. 1481-1488, May 2015, doi: 10.1016/j.sbspro.2015.02.296.

14. B. A. Al-Sheeb, A. M. Hamouda, and G. M. Abdella, "Modeling of student academic achievement in engineering education using cognitive and noncognitive factors,"J. Appl. Res. High. Educ., vol. 11, no. 2, pp. 178-198, Jan. 2019, doi: 10.1108/JARHE-102017-0120.

15. O. W. Adejo and T. Connolly, "Predicting student academic performance using multi-model heterogeneous ensemble approach," J. Appl. Res. High. Educ., vol. 10, no. 1, pp. 61-75, Feb. 2018, doi: 10.1108/JARHE-09-2017-0113.

16. V. K. G, "Prediction of Source Code Quality Using Cyclomatic Complexity and Machine Learning," Int. J. Adv. Trends Comput. Sci. Eng., vol. 9, no. 4, pp. 4409-4413, Aug. $2020, \quad$ doi: 10.30534/ijatcse/2020/34942020.

17. Bina Nusantara University Jakarta, Indonesia and R. Jayadi, "Employee Performance Prediction using Naïve Bayes," Int. J. Adv. Trends Comput. Sci. Eng., vol. 8, no. 6, pp. 3031-3035, Dec. 2019, doi: 10.30534/ijatcse/2019/59862019.

18. Colab research framework, URL: https://colab.research.google.com/

19. Prakash V.C., Sastry J.K.R., Kantha Rao V., VineethaT., Harika V., Reddy A.A. ,'A critical study on 
applicability of sokoban game for building cognitive model of a student for career assessment',International Journal of Engineering and Technology(UAE),7 (1.1),PP. 260-264, 2018.

20. Anjali Devi S., Vishnu Priya M.,Akhila P., Vasundhara $\mathrm{N}$.,'Analysis and prediction of student placement for improving the education standards', International Journal of Engineering and Technology(UAE), 7 (2.7),PP. 303-306, 2018.

21. Chandra Prakash V., Sastry J.K.R., Anusha K., Ashok Kumar P., Venkatesh N., Ravi Teja G. ,'Expert system for building cognitive model of a student using 8puzzle game and for career assessment', International Journal of Engineering and Technology(UAE), 7 (0),PP. 113-117, 2018.

22. Ravi Kumar T., YasaswiniP., Rafi G., Krishna D.V.,'Comparative analysis on job prediction of students based on resume using data mining techniques',International Journal of Engineering and Technology(UAE), 7 (2),PP. 1100-1103, 2018.

23. Kuswanth V.S., Chaitanya G.K., Babu B.S., Soundharya U.L. , 'Machine learning approach for student career assessment in the modern world', International Journal of Recent Technology and Engineering, 7(6), PP.178183, 2019.

24. Anusha M., Karthik K., Padmini Rani P., Srikanth V., 'Prediction of student performance using machine learning', International Journal of Engineering and Advanced Technology, 8(6), PP.247-255, 2019.

25. Mohiddin S.K., Kumar P.S., Sai S.A.M., Santhi M.V.B.T., 'Machine learning techniques to improve the results of student performance', International Journal of Innovative Technology and Exploring Engineering, 8(5), PP.590-594, 2019.

26. Chand T.J.S., Manideep T., Surya M.S., Rao V.K., 'An expert system to predict readiness of a student for campus placements using neural networks', International Journal of Engineering and Advanced Technology, 8(4), PP.499-502, 2019.

27. Chandra Prakash V., Sastry J.K.R., Kantharao V., Sriharshini V., Sriram G., Ganesh C.H.V.S.,'An expert system to assess memory power of a student for selection of a suitable career',Journal of Advanced Research in Dynamical and Control Systems,9(Special Issue 6),PP.309-321, 2017.

28. Myla S., Marella S.T., Goud A.S., Ahammad S.H., Kumar G.N.S., Inthiyaz S., 'Design decision taking system for student career selection for accurate academic system', International Journal of Scientific and Technology Research, 8(9), PP.2199-2206, 2019.

29. A. O. Gamao, Bobby D. Gerardo, "Prediction-Based Model for Student Dropouts using Modified Mutated Firefly Algorithm," Int. J. Adv. Trends Comput. Sci. Eng., vol. 8, no. 6, pp. 3461-3469, Dec. 2019, doi: 10.30534/ijatcse/2019/122862019.

30. V. Gampala and S. Malempati, "EARLY PREDICTION AND ANALYSIS OF COVID-19 PANDEMIC OUTBREAK USING DEEP LEARNING TECHNIQUE," J. Crit. Rev., vol. 7, no. 18, pp. 2971-2981, 2020. 